\title{
Health-related quality of life in Romanian postmenopausal women with osteoporosis and fragility fractures
}

This article was published in the following Dove Press journal:

Clinical Interventions in Aging

\author{
Alina Deniza Ciubean ${ }^{1,2}$ \\ Rodica Ana Ungur ${ }^{2,3}$ \\ Laszlo Irsay ${ }^{2,3}$ \\ Viorela Mihaela Ciortea ${ }^{2,3}$ \\ Ileana Monica Borda ${ }^{2,3}$ \\ loan Onac ${ }^{2,3}$ \\ Stefan Cristian Vesa' \\ Anca Dana Buzoianu' \\ 'Department of Pharmacology, \\ Toxicology and Clinical Pharmacology, \\ luliu Hațieganu University of Medicine \\ and Pharmacy, Cluj-Napoca, Romania; \\ ${ }^{2}$ Department of Rehabilitation, \\ Clinical Rehabilitation Hospital, \\ Cluj-Napoca, Romania; ${ }^{3}$ Department \\ of Rehabilitation Medicine, luliu \\ Hațieganu University of Medicine and \\ Pharmacy, Cluj-Napoca, Romania
}

Correspondence: Rodica Ana Ungur Department of Rehabilitation, Clinical Rehabilitation Hospital, 46-50, Viilor Street, Cluj-Napoca, PC 400437, Romania

Tel +40 26420702 I ext I57

Email rodica.ana.ungur@gmail.com
Objectives: Osteoporosis is a common skeletal disorder characterized by decreased bone mass and increased susceptibility to fractures, which are associated with pain and decrease in physical function, social function, and well-being, which are all aspects of quality of life (QoL). The purpose of this study was to evaluate the burden of osteoporosis and fragility fractures in Romanian postmenopausal women from Cluj County using the 36-Item Short Form Health Survey (SF-36) and Quality of life questionnaire of the European Foundation for Osteoporosis (QUALEFFO-41) questionnaires.

Materials and methods: An analytical cross-sectional study on 364 postmenopausal women was carried out between June 2016 and August 2017 in the Clinical Rehabilitation Hospital in Cluj-Napoca, Cluj County, Romania. Data were collected by interview and from the medical documents: clinical and demographic data, personal medical history, risk factors for osteoporosis, and bone mineral density at the lumbar spine and femur. The patients included in the study were asked to complete the Romanian versions of the SF-36 and QUALEFFO-41 questionnaires.

Results: Women with osteoporosis had significantly lower scores in the SF-36 domains $(P<0.001)$ than healthy controls. In the osteoporosis group, a significant association was found in the SF-36 pain domain, where women with a history of fracture had higher scores $(P=0.035)$. As for QUALEFFO-41, a statistical significance was found in the total score $(P<0.05)$, revealing a significantly lower QoL in osteoporotic women with a history of fracture.

Conclusion: The SF-36 scores registered a loss of QoL in women with osteoporosis. The QUALEFFO-41 total score was significantly lower in the osteoporosis associated with fracture, revealing a lower health-related QoL in these patients.

Keywords: osteoporosis, quality of life, fragility fractures, QUALEFFO-41, SF-36

\section{Introduction}

Osteoporosis is a common skeletal disorder characterized by reduced bone mass and disruption of bone microarchitecture, resulting in an increased bone fragility and a high fracture risk. ${ }^{1}$ It was estimated in 2010 that $21 \%$ of women from the European Union (EU) with age between 50 and 84 years have osteoporosis. ${ }^{2}$ The prevalence of postmenopausal osteoporosis in Romania is estimated to be $11.5 \%$, which means that one in three Romanian women would be osteoporotic or osteopenic after the age of 55 years. ${ }^{3}$

Osteoporosis, alongside osteoarthritis, sarcopenia, and frailty, is considered to be a part of the so-called musculoskeletal aging phenotype. All these entities are associated with adverse outcomes such as falls, fractures, functional decline, and increased mortality, which could highly affect independence levels and quality of life (QoL) of an individual, with a consequent significant public health burden. ${ }^{4,5}$ 
The most important clinical complications of osteoporosis are fragility fractures, mostly occurring in the hip, wrist, and vertebral bodies. Worldwide, it is estimated that more than 8.9 million fractures occur annually due to osteoporosis, and more than one-third of them occur in the EU, resulting in a fragility fracture every 3 seconds. All fragility fractures are associated with pain and decrease in physical function, social function, and well-being, which are all aspects of QoL. However, in many individuals, osteoporosis exists in the absence of fractures. ${ }^{3,6}$

QoL is a broad concept with multiple dimensions that reflects all aspects of an individual's well-being (health status and the environmental, spiritual, and economical issues). Health-related quality of life (HRQoL) is more specific and is concerned with health aspects such as physical, emotional, and social well-being and the effect of an illness and/or treatment on these parameters. HRQoL may be measured for the assessment of the burden of the disease to estimate the cost-effectiveness of different treatments and to evaluate treatment effect in clinical trials. ${ }^{7}$

Assessing HRQoL has been considered an important marker of the clinical evolution of patients with osteoporosis and fractures. Physical, emotional, and psychological incapacity, combined with the pain that results from hip, spine, or wrist fractures, can alter QoL. ${ }^{8}$

HRQoL instruments, which are validated questionnaires completed by the individual, are oriented toward either general health or a specific disease or condition.

One of the most widely used generic questionnaires to quantify HRQoL is the 36-Item Short Form Health Survey (SF-36). SF-36 is a generic instrument with scores based on responses to individual questions that are summarized in eight domains, each of which measures a health concept: pain, physical functioning, general health perception, role limitation-physical aspect, role limitation-emotional aspect, energy/fatigue, social functioning, and emotional health. These eight domains are scored from 0 to 100 , with higher scores reflecting a better QoL. ${ }^{4,9}$

An osteoporosis-specific instrument for measuring QoL has been developed. Quality of life questionnaire of the European Foundation for Osteoporosis (QUALEFFO-41) is a self-administered, specific questionnaire designed to be used in patients with osteoporosis. It consists of 41 questions in the following domains: pain, physical function (activities of daily living, jobs around the house, mobility), social function, general health perception, and mental function. Domain scores are calculated by averaging the answers of one domain and transforming the values to a 0-100 scale, with higher scores reflecting a lower QoL. ${ }^{10-12}$
The purpose of our study was to evaluate the burden of osteoporosis in Romanian postmenopausal women using a generic and a disease-specific HRQoL instrument. Furthermore, we examined the impact of common fragility fractures (vertebral, hip, wrist and humerus) on QoL in postmenopausal Romanian women with primary osteoporosis as measured by the disease-specific QUALEFFO-41 instrument and the domains of the SF-36.

\section{Materials and methods}

An analytical cross-sectional study was carried out between June 2016 and August 2017. The study included a total of 364 postmenopausal women, of whom 228 women had been previously diagnosed with primary osteoporosis. Osteoporosis was defined by dual-energy X-ray absorptiometry (DEXA) measurement as a T-score lower than -2.5 (the difference between the measured BMD and the mean value of young adults, expressed in SDs), according to the WHO Study Group definition. The rest of 136 women were healthy age-matched controls. All the women included in the study were recruited during routine outpatient visit in the Clinical Rehabilitation Hospital in Cluj-Napoca, Romania.

The inclusion criteria for both groups were as follows: 1 ) at least 2 years since menopause and 2 ) a recent (not older than 3 months) bone mineral density (BMD) measurement using DEXA at the lumbar spine and femur. The control group was recruited from patients who referred to the clinic for degenerative pathologies (eg, hip or knee osteoarthritis, shoulder disorders), had no history of fracture at any site, and had normal BMD values on DEXA measurement.

Exclusion criteria were as follows: 1) history of metabolic bone diseases (eg, hyperparathyroidism, osteomalacia, Paget's disease); 2) comorbidities that would interfere with the patients' ability to fully participate in this study (eg, severe psychiatric, emotional, cognitive, or speech impairments that would prevent them from answering questionnaires); 3 ) concurrent rheumatic diseases that could be the primary cause of back pain (eg, severe scoliosis, lumbar disc disease, fibromyalgia); 4) secondary osteoporosis (eg, rheumatoid arthritis, celiac disease, kidney failure, hyperthyroidism, diabetes); and 5) malignancy or bone metastasis.

Data were collected by interview and from the medical documents of each patient included in the study: age; weight and height; body mass index (BMI); history of vertebral, hip, wrist, or humerus fracture; current smoking; alcohol consumption (more than three units daily); age at menopause; years of amenorrhea; history of parental hip fracture; lumbar 
spine (L1-L4) BMD; and femoral neck BMD. In addition, for each patient included in the study, the 10-year probability of fracture was calculated using the FRAX ${ }^{\circledR}$ algorithm.

Two types of HRQoL questionnaires were used: a general health assessment (SF-36) and a disease-targeted instrument (QUALEFFO-41). All patients included in the study were asked to complete the Romanian version of the SF-36. Furthermore, women diagnosed with osteoporosis were asked to complete the Romanian version of QUALEFFO-41.

Patient data were entered in the Microsoft Office Excel 2010 program, and statistical analysis was performed using MedCalc statistical software version 17.9.7 (MedCalc Software bvba, Ostend, Belgium; http://www.medcalc.org; 2017) and SPSS for Windows, version 20. Quantitative data were tested for normality of distribution and expressed as mean \pm SD or median and IQR, whenever appropriate. Qualitative data were expressed as frequency and percentage. Comparison between groups was performed using Student's $t$-test, MannWhitney test, or chi-squared test, whenever appropriate. Correlations between two groups were tested using Spearman's rho correlation coefficient. A $P$-value $<0.05$ was considered as statistically significant.

The study was approved by the ethics committee of the University of Medicine and Pharmacy "Iuliu Haţieganu" (approval no 248/09.06.2016). All participants were informed of the characteristics of the study, and all of them gave signed informed consent prior to inclusion. This study was conducted in accordance with the Declaration of Helsinki.

\section{Results}

For the HRQoL analysis, 364 postmenopausal women met the inclusion criteria. Women were divided into two groups according to diagnosis after the DEXA measurement: osteoporosis $(n=228)$ and healthy controls $(n=136)$. Furthermore, the 228 osteoporotic women were divided into two groups based on their history of fracture: with fracture $(n=132)$ and without fracture $(n=96)$.

All 364 women included in the study were asked to complete the general health assessment SF-36 questionnaire, and women from the osteoporotic group were asked to also complete the disease-specific QUALEFFO-41 questionnaire.

The age of the study participants ranged from 46 to 85 years in both groups. The mean $( \pm \mathrm{SD})$ age of the osteoporosis and control groups was 65.5 years ( \pm 7.39 years) and 63.45 years ( \pm 8.16 years), respectively. Analysis of the anthropometric and clinical data showed that the mean age at menopause did not significantly differ between the study groups $(P=0.045)$, but when analyzing the number of years since menopause (time of amenorrhea), the results show that the mean $( \pm \mathrm{SD})$ years since menopause in the osteoporosis group was 18.25 years $( \pm 8.36$ years $)$ and that in the control group was 15.08 years $( \pm 8.82$ years $)$, which reached a high statistical significance $(P=0.001)$. The mean BMI was 27.05 $\mathrm{kg} / \mathrm{m}^{2}$ in the osteoporosis group and $30.56 \mathrm{~kg} / \mathrm{m}^{2}$ in the control group.

In the osteoporosis group, the mean $( \pm \mathrm{SD})$ bone mineral density (BMD) was $0.851 \mathrm{~g} / \mathrm{cm}^{2}\left( \pm 0.11 \mathrm{~g} / \mathrm{cm}^{2}\right)$ in the lumbar spine (L1-L4) and $0.751 \mathrm{~g} / \mathrm{cm}^{2}\left( \pm 0.10 \mathrm{~g} / \mathrm{cm}^{2}\right)$ in the femoral neck. In addition, osteoporotic women had a higher 10-year risk of developing a major osteoporotic fracture or a hip fracture than the control group $(P<0.005$ and $P<0.001$, respectively) based on $\mathrm{FRAX}^{\circledR}$ algorithm.

Previous fractures were recorded only in the osteoporotic group $(n=228)$. There was no history of previous fractures in the control group. The frequency of fractures was $57.9 \%$ $(n=132)$. Among them, 41.2\% $(n=94)$ were located in the vertebral bodies, $4.4 \%(n=10)$ in the hip, $21.1 \%(n=48)$ in the wrist, and $5.7 \%(n=13)$ in the humerus.

The main characteristics of the women included in the study are given in Table 1 .

Regarding QoL, postmenopausal women with osteoporosis had significantly lower scores in the SF-36 domains $(P<0.001)$, except for the energy/fatigue domain, which did not present significant difference between groups $(P=0.192)$. The SF-36 scores are expressed as median and IQR. Results per domains are given in Table 2.

In the osteoporosis group, when comparing QoL between women with a history of fracture and those without, no significant association was found between SF-36 domains $(P>0.05)$, except for the pain domain. Women with a history of fracture had higher scores in the pain domain $(P=0.035)$.

As for the QUALEFFO-41 domains, statistical significance was found in the following domains: leisure/social activities, mental function, and total score. The leisure/social activities item showed a significant association between groups $(P=0.002)$, meaning that women who had a previous fracture due to osteoporosis have a highly significant lower participation in leisure or social activities than women without a history of fracture. As for the mental function domain, the no fracture osteoporosis group revealed higher scores $(P=0.019)$. When comparing the total scores of QUALEFFO-41 between the two groups, a higher score was found in the fracture group, meaning a lower QoL $(P=0.05)$. 
Table I Clinical characteristics of women included in the study

\begin{tabular}{|c|c|c|c|}
\hline Variables & $\begin{array}{l}\text { Osteoporosis } \\
(n=228)\end{array}$ & $\begin{array}{l}\text { Controls } \\
(n=136)\end{array}$ & $P$-value \\
\hline Age, mean $\pm S D$ (years) & $65.5 \pm 7.39$ & $63.45 \pm 8.16$ & - \\
\hline BMI, mean \pm SD $\left(\mathrm{kg} / \mathrm{m}^{2}\right)$ & $27.05 \pm 4.74$ & $30.56 \pm 5.40$ & $<0.001$ \\
\hline Age at menopause, mean $\pm S D$ (years) & $47.26 \pm 4.84$ & $48.35 \pm 4.88$ & 0.045 \\
\hline Time of amenorrhea, mean $\pm \mathrm{SD}$ (years) & $18.25 \pm 8.36$ & $15.08 \pm 8.82$ & 0.001 \\
\hline Previous fracture, $\mathrm{n}(\%)$ & I 32 (57.9) & - & - \\
\hline Vertebral fracture, $\mathrm{n}(\%)$ & $94(41.2)$ & - & - \\
\hline Hip fracture, n (\%) & $10(4.4)$ & - & - \\
\hline Wrist fracture, n (\%) & $48(21.1)$ & - & - \\
\hline Humerus fracture, $\mathrm{n}(\%)$ & $13(5.7)$ & - & - \\
\hline Current smoking, n (\%) & $10(4.4)$ & $6(4.4)$ & - \\
\hline Alcohol consumption $>3$ units/day, $n$ (\%) & $3(1.3)$ & - & - \\
\hline Parent fractured hip, n (\%) & $13(5.6)$ & $8(5.8)$ & - \\
\hline Lumbar spine (LI-L4) BMD, mean \pm SD $\left(\mathrm{g} / \mathrm{cm}^{2}\right)$ & $0.85 I \pm 0.11$ & $1.116 \pm 0.15$ & $<0.001$ \\
\hline Femoral neck BMD, mean \pm SD $\left(g / \mathrm{cm}^{2}\right)$ & $0.75 I \pm 0.10$ & $0.969 \pm 0.21$ & $<0.001$ \\
\hline FRAX $^{\circledR}-10$-year risk of major osteoporotic fracture, mean $\pm S D(\%)$ & $8.04 \pm 4.68$ & $4.34 \pm 2.47$ & 0.005 \\
\hline $\mathrm{FRAX}^{\circledR}-10$-year risk of hip fracture, mean \pm SD $(\%)$ & $2.76 \pm 2.97$ & $0.82 \pm 1.47$ & $<0.001$ \\
\hline
\end{tabular}

Note: Bold text represent statistical significance.

Abbreviations: BMI, body mass index; BMD, bone mineral density.

Table 3 gives the comparison of QoL scores in the QUALEFFO-41 and SF-36 questionnaires between osteoporotic women with and without fragility fractures. Furthermore, when calculating the Spearman correlation coefficient between scores of the QUALEFFO-41 and SF-36 domains, there was no significant correlation between scores in the five QUALEFFO-41 domains (pain, physical function, social function, general health perception, and mental function) and the corresponding SF-36 domains $(P>0.05$; data not shown).

\section{Discussion}

This study evaluated HRQoL in Romanian postmenopausal women with osteoporosis using the SF-36 and QUALEFFO-41 instruments. Given the fact that QUALEFFO-41 is validated as an osteoporosis-specific questionnaire, we did not evaluate QoL with this instrument in the healthy controls but only in the osteoporosis group, and we used the data to compare the impact of the disease and its complications in osteoporotic women with and without history of fragility fractures at the elective sites (vertebral bodies, hip, wrist and humerus).

It is a known fact that osteoporotic fractures are very common and are associated with high direct costs to the global economy, as their numbers will increase globally with the aging population. ${ }^{13}$ They cause pain and loss of function in the area where they occur, but each type comes with certain and specific complications. Hip fracture is considered to be the most serious osteoporotic fracture. Most are caused by a fall from the standing position, although they sometimes occur spontaneously. In addition to pain and loss of function, hip fractures nearly always require hospitalization, with a slow and often incomplete recovery. ${ }^{14}$ Furthermore, hip fractures are linked to increased mortality..$^{15}$ Vertebral fractures often recur, and the consequent disability increases with their number. They may cause pain, loss of height, and progressive curvature of the spine (kyphosis). The consequences

Table 2 Comparison of QoL scores in the SF-36 questionnaire between women with osteoporosis and healthy controls

\begin{tabular}{|c|c|c|c|}
\hline \multirow[t]{2}{*}{ SF-36 domains } & \multirow{2}{*}{$\begin{array}{l}\text { Osteoporosis }(\mathrm{n}=\mathbf{2 2 8}) \\
\text { Median (IQR) }\end{array}$} & \multirow{2}{*}{$\begin{array}{l}\text { Controls }(n=136) \\
\text { Median (IQR) }\end{array}$} & \multirow[t]{2}{*}{$P$-value } \\
\hline & & & \\
\hline Physical functioning & $50(40 ; 55)$ & $55(50 ; 60)$ & $<0.001$ \\
\hline Role limitation due to physical health & $25(25 ; 50)$ & $50(25 ; 75)$ & $<0.001$ \\
\hline Role limitation due to emotional problems & $33.33(33.33 ; 66.66)$ & $66.66(33.33 ; 100)$ & $<0.001$ \\
\hline Energy/fatigue & $55(45 ; 58.75)$ & $55(45 ; 60)$ & 0.192 \\
\hline Emotional well-being & $56(52 ; 60)$ & $60(52 ; 64)$ & $<0.001$ \\
\hline Social functioning & $50(25 ; 62.5)$ & $62.5(62.5 ; 75)$ & $<0.001$ \\
\hline Pain & $45(45 ; 67.5)$ & $72.5(55 ; 77.5)$ & $<0.001$ \\
\hline General health & $35(30 ; 50)$ & $70(55 ; 75)$ & $<0.001$ \\
\hline
\end{tabular}

Note: Bold text represent statistical significance.

Abbreviations: QoL, quality of life; SF-36, 36-Item Short Form Health Survey. 
Table 3 Comparison of QoL scores in the QUALEFFO-4I and SF-36 questionnaires between osteoporotic women with and without fragility fractures

\begin{tabular}{|c|c|c|c|}
\hline Domains & $\begin{array}{l}\text { Osteoporosis with fracture } \\
(n=132)\end{array}$ & $\begin{array}{l}\text { Osteoporosis without fracture } \\
(n=96)\end{array}$ & $P$-value \\
\hline SF-36 & Median (IQR) & Median (IQR) & \\
\hline Physical functioning & $50(40 ; 55)$ & $50(40 ; 55)$ & 0.306 \\
\hline Role limitation due to physical health & $25(25 ; 50)$ & $25(25 ; 50)$ & $0.74 I$ \\
\hline Role limitation due to emotional problems & $33.33(33.33 ; 66.66)$ & $33.33(33.33 ; 66.66)$ & 0.230 \\
\hline Energy/fatigue & $55(50 ; 60)$ & $52.5(45 ; 55)$ & 0.317 \\
\hline Emotional well-being & $56(52 ; 60)$ & $56(52 ; 60)$ & 0.299 \\
\hline Social functioning & $50(37.5 ; 62.5)$ & $50(25 ; 62.5)$ & 0.314 \\
\hline Pain & $45(45 ; 67.5)$ & $45(35 ; 57.5)$ & 0.035 \\
\hline General health & $40(30 ; 50)$ & $35(30 ; 50)$ & 0.792 \\
\hline \multicolumn{4}{|l|}{ QUALEFFO-4I } \\
\hline Pain & $55(30 ; 65)$ & $50(30 ; 65)$ & 0.446 \\
\hline Activities of daily living & $31.25(25 ; 37.5)$ & $31.25(18.75 ; 37.5)$ & 0.427 \\
\hline Jobs around the house & $40(30 ; 55)$ & $40(20 ; 55)$ & 0.96 \\
\hline Mobility & $28.12(21.87 ; 40.62)$ & $28.12(18.75 ; 46.87)$ & 0.446 \\
\hline Leisure, social activities & 54.28 (30.7I; 73.57) & $40(27.14 ; 56.78)$ & 0.002 \\
\hline General health perception & $75(66.66 ; 83.33)$ & $66.66(50 ; 83.33)$ & 0.105 \\
\hline Mental function & $44.44(30.55 ; 52.78)$ & $50(36.11 ; 57.63)$ & 0.019 \\
\hline Total score & $44.48(39.43 ; 50.68)$ & $42.34(36.38 ; 47.45)$ & 0.05 \\
\hline
\end{tabular}

Note: Bold text represent statistical significance.

Abbreviations: QoL, quality of life; SF-36, 36-Item Short Form Health Survey; QUALEFFO-4I, Quality of life questionnaire of the European Foundation for Osteoporosis.

of kyphosis include difficulties in performing activities of daily living, respiratory problems, and a loss of self-esteem due to change in body shape. ${ }^{16-18}$ Hip and vertebral fractures are associated with impaired QoL and a $20 \%$ reduction in survival. Distal radius fractures have a functional recovery usually good or excellent. Approximately $1 \%$ of patients with a forearm fracture become dependent as a result of the fracture, but nearly half report only fair or poor functional outcome at 6 months. ${ }^{19}$

However, more importantly, besides their location, functional outcome, and specific complications, a fracture may decrease mobility and social interaction and cause emotional problems, which are all characteristics that determine QoL. Fracture events can affect the physical and mental domains of QoL to different degrees depending on the type and severity of the fracture. ${ }^{20}$ Fracture patients experience psychological sequelae, such as anxiety, fear, depression, reduced selfesteem, and social isolation. ${ }^{21}$ Hagino et a ${ }^{22}$ concluded that loss of QoL is more severe after hip or vertebral fractures than after a wrist fracture.

A study performed on 60,393 women aged $>55$ years showed that women with prior fractures of the hip, vertebral bodies or humerus had worse HRQoL than those without history of fracture as measured by the SF-36 and EQ-5D questionnaires. In addition, the same authors concluded that a history of fragility fracture has the same effect on reduction in HRQoL as does the presence of diabetes, arthritis, or lung disease. ${ }^{23}$
Romagnoli et $\mathrm{l}^{24}$ and Bianchi et $\mathrm{a}^{25}$ showed a decreased QoL in women with osteoporosis independent of the presence of fracture in different domains of QUALEFFO-41.

It is important to mention that many studies often do not differentiate between osteoporosis (low BMD) and fracture. The two situations may present different problems regarding HRQoL. The perception of health in patients who are diagnosed with osteoporosis could be altered due to concerns that their condition may predispose them to fracture. On the other hand, the occurrence of a fracture could make a patient aware of the diagnosis and may contribute more to the physical and pain domains of the HRQoL. ${ }^{26}$ Interestingly, the present study showed higher QUALEFFO-41 scores in the mental domain for the osteoporosis group without a previous fracture than those who sustained at least one fragility fracture, possibly revealing the emotional impact of receiving this diagnosis. As pharmacological treatment options are available in Romania, further interventions are required toward better psychological support and patient education for a better long-term management of this disease.

Other studies have shown a correlation between the results of generic and specific HRQoL scales in postmenopausal women with osteoporosis. A cross-sectional study from Brazil showed that women with osteoporosis had a worse QoL than women in the control group in the SF-36 and QUALEFFO-41 domains. The same authors stated that there was a significant correlation between domains from 
both questionnaires. ${ }^{27}$ In the present study, we did not find an association between domains of both instruments used.

A more recent study by the same group of authors from Brazil used QUALEFFO-41 to assess QoL in 126 postmenopausal osteoporotic women, of which 43 had a history of at least one vertebral fracture. Their results show that there was a significant QoL impairment in osteoporotic women and that it was not influenced by the presence of vertebral fractures. However, they found a direct correlation between the number of vertebral fractures and worse QoL scores. ${ }^{28}$

Interestingly, Palacios et $\mathrm{al}^{29}$ concluded that postmenopausal women with osteoporosis have a lower QoL, and this loss is greater in women with prior osteoporotic fracture, as measured by the generic SF-12 and the menopause-specific scale Cervantes.

In addition, other studies have shown that a worse QoL is dependent on the number of fractures and spinal fracture site. Oleksik et al ${ }^{30,31}$ showed in two studies that QUALEFFO-41 domain scores are higher in patients with low BMD and vertebral fractures. In addition, Silverman et al showed that both prevalent and incident vertebral fractures were associated with decreases in HRQoL and that increasing numbers of prevalent vertebral fractures were associated with progressive decreases in HRQoL. Prevalent lumbar vertebral fractures have a higher negative impact on QoL than prevalent thoracic vertebral fractures. ${ }^{32}$

Wilson et $\mathrm{al}^{26}$ conducted a systematic review that included 27 articles and showed that patients without vertebral fractures had worse scores in the SF-36 and QUALEFFO-41 domains than those in the control group.

Another systematic review and meta-analysis of 16 observational studies was conducted by Al-Sari et al, ${ }^{33}$ which also demonstrated that there is a clear association between physical health status and vertebral fractures, regardless of age.

It is important to highlight that this study was not designed to assess the impact of vertebral fractures alone as most QoL studies in osteoporosis do. Moreover, we did not consider the number and location of vertebral fractures due to a small number of participants. Although this study does not discriminate between spine, hip, wrist or humerus fractures, other studies have shown that women who suffered a hip or vertebral fracture have a worse HRQoL. ${ }^{34,35}$

The generic instrument SF-36 demonstrated its capability to register loss of HRQoL in Romanian postmenopausal women with osteoporosis but not in women with prior fragility fractures. On the contrary, Roux et $\mathrm{al}^{36}$ found significant reductions in SF-36 physical function domain for spine fractures and a borderline association with non-hip and non-vertebral fractures. In the present study, domains of QUALEFFO-41 did not show significant differences between osteoporotic women with and without a fragility fracture, except for the leisure/social activities and mental function domain. In addition, Kerschan-Schindl et $\mathrm{al}^{37}$ showed that when using a disease-targeted QoL questionnaire, problems associated with low emotional well-being due to osteoporotic vertebral fractures are better reflected. The QUALEFFO-41 total score was significantly lower in the osteoporosis with fracture group, revealing a lower HRQoL than in osteoporotic women without a history of fracture.

Borgström et al ${ }^{38}$ evaluated QoL in 2,808 patients with fractures due to osteoporosis from 11 countries and concluded that there are important variations in the QoL after a fracture between countries and it could be related to differences in management and treatment of fractures and different perceptions on QoL.

To our knowledge, this is the first Romanian study to assess both a disease-specific and a generic instrument in postmenopausal women with osteoporosis. As the burden of osteoporosis is increasing worldwide, results from the current research are important for future burden-of-disease and cost-of-illness studies. In addition, it reinforces the need for better auxiliary treatment options provided to Romanian postmenopausal women with osteoporosis (eg, rehabilitation, occupational therapy, support groups, patient education). In the future, population-based studies are required for a better evaluation of HRQoL impairments in Romanian osteoporotic women with or without fragility fractures.

The main limitations of our study were its cross-sectional design, low number of participants, and the fact that the patients were selected from one hospital setting, which could cause an overestimation of risks and consequences of osteoporosis in Romanian postmenopausal women. In addition, the study design allows association between variables without considering their chronological order, meaning that the inclusion of women with a history of fracture is a bias in HRQoL assessment, as it is important to know what amount of time has passed since the event, mainly in the presence of vertebral fractures that can be asymptomatic and found incidentally on a simple X-ray. Finally, the impact of comorbidities, lifestyle, and concomitant drug therapy was not assessed.

\section{Conclusion}

1. Romanian postmenopausal women with osteoporosis have a lower HRQoL than healthy controls as measured by the SF-36 instrument and total score of QUALEFFO-41. 
2. The pain domain in SF-36 showed higher scores in the osteoporosis group with a history of fracture, reflecting a better QoL, while the QUALEFFO-41 pain domain showed no difference between groups.

3. Higher QUALEFFO-41 scores were found in osteoporotic women with fractures in the leisure/social activities domain, showing a lower HRQoL in social participation, than in osteoporotic women without a history of fracture.

4. Women diagnosed with osteoporosis, but did not sustain a fragility fracture, have lower QUALEFFO-41 scores in the mental function domain, possibly revealing the emotional impact of the diagnosis and its future possible complications.

5. Future work should be directed toward assessing whether low BMD as a single factor is suffice to determine lower QoL or there are other factors, such as fractures and their characteristics, or other comorbidities that contribute toward worse health-related QoL in postmenopausal Romanian women with osteoporosis.

6. An important part of long-term management of a chronic pathology like osteoporosis is improving HRQoL by all aspects and by any interventions required.

\section{Acknowledgment}

The present article processes results from the first author's doctoral thesis.

\section{Disclosure}

The authors report no conflicts of interest in this work.

\section{References}

1. Kanis JA, Adachi JD, Cooper C, et al. Standardising the descriptive epidemiology of osteoporosis: recommendations from the Epidemiology and Quality of Life Working Group of IOF. Osteoporos Int. 2013; 24(11):2763-2764.

2. Hernlund $\mathrm{E}$, Svedbom A, Ivergård $\mathrm{M}$, et al. Osteoporosis in the European Union: medical management, epidemiology and economic burden. Arch Osteoporos. 2013;8(1-2):136.

3. Svedbom A, Hernlund $\mathrm{E}$, Ivergård $\mathrm{M}$, et al. Osteoporosis in the European Union: a compendium of country-specific reports. Arch Osteoporos. 2013;8:137

4. Beaudart $\mathrm{C}$, Biver $\mathrm{E}$, Bruyère $\mathrm{O}$, et al. Quality of life assessment in musculo-skeletal health. Aging Clin Exp Res. 2018;30(5):413-418.

5. Dawson A, Dennison E. Measuring the musculoskeletal aging phenotype. Maturitas. 2016;93:13-17.

6. Johnell O, Kanis JA. An estimate of the worldwide prevalence and disability associated with osteoporotic fractures. Osteoporos Int. 2006; 17(12):1726-1733.

7. Michalos AC. Social indicators research and health-related quality of life research. In: Connecting the Quality of Life Theory to Health, Wellbeing and Education. New York: Springer International Publishing. 2017: 22-58.

8. Greendale GA, Barrett-Connor E, Ingles S, Haile R. Late physical and functional effects of osteoporotic fracture in women: the Rancho Bernardo Study. J Am Geriatr Soc. 1995;43(9):955-961.
9. Ware JE, Sherbourne CD. The MOS 36-item short-form health survey (SF-36). I. Conceptual framework and item selection. Med Care. 1992; 30(6):473-483.

10. Lips P, Cooper C, Agnusdei D, et al. Quality of life in patients with vertebral fractures: validation of the quality of life questionnaire of the European foundation for osteoporosis (QUALEFFO). Osteoporosis International. 1999;10(2):150-160.

11. Irsay L, Nițu AD, Ungur R. The impact of isokinetic exercises on the quality of life in patients with primary osteoporosis. Palestrica of the Third Millennium Civilization \& Sport. 2011;12(3):215-220.

12. Brăilescu CM, Nica AS, Mologhianu G. Effects of a medical kinetic program on QoL and reactive depression in a group of women with postmenopausal osteoporosis. Palestrica of the Third Millennium Civilization \& Sport. 2017;18(1):13-19.

13. Harvey N, Dennison E, Cooper C. Osteoporosis: impact on health and economics. Nat Rev Rheumatol. 2010;6(2):99-105.

14. Stone KL, Seeley DG, Lui LY, et al. BMD at multiple sites and risk of fracture of multiple types: long-term results from the Study of Osteoporotic Fractures. J Bone Miner Res. 2003;18(11):1947-1954.

15. Hallberg I, Bachrach-Lindström M, Hammerby S, Toss G, Ek AC. Health-related quality of life after vertebral or hip fracture: a seven-year follow-up study. BMC Musculoskelet Disord. 2009;10(1):135.

16. Johnell O, Oden A, Caulin F, Kanis JA. Acute and long-term increase in fracture risk after hospitalization for vertebral fracture. Osteoporos Int. 2001;12(3):207-214.

17. Bennell KL, Matthews B, Greig A, et al. Effects of an exercise and manual therapy program on physical impairments, function and quality-of-life in people with osteoporotic vertebral fracture: a randomised, singleblind controlled pilot trial. BMC Musculoskelet Disord. 2010;11:36.

18. Sanfélix-Genovés J, Hurtado I, Sanfélix-Gimeno G, Reig-Molla B, Peiró S. Impact of osteoporosis and vertebral fractures on quality-oflife. A population-based study in Valencia, Spain (The FRAVO Study). Health Qual Life Outcomes. 2011;9(1):20.

19. Johnell O, Kanis JA, Odén A, et al. Fracture risk following an osteoporotic fracture. Osteoporos Int. 2004;15(3):175-179.

20. Fechtenbaum J, Cropet C, Kolta S, Horlait S, Orcel P, Roux C. The severity of vertebral fractures and health-related quality of life in osteoporotic postmenopausal women. Osteoporos Int. 2005;16(12):2175-2179.

21. Madureira MM, Ciconelli RM, Pereira RM. Quality of life measurements in patients with osteoporosis and fractures. Clinics. 2012;67(11): $1315-1320$.

22. Hagino H, Nakamura T, Fujiwara S, Oeki M, Okano T, Teshima R. Sequential change in quality of life for patients with incident clinical fractures: a prospective study. Osteoporos Int. 2009;20(5):695-702.

23. Adachi JD, Adami S, Gehlbach S, et al. Impact of prevalent fractures on quality of life: baseline results from the global longitudinal study of osteoporosis in women. Mayo Clin Proc. 2010;85(9):806-813.

24. Romagnoli E, Carnevale V, Nofroni I, et al. Quality of life in ambulatory postmenopausal women: the impact of reduced bone mineral density and subclinical vertebral fractures. Osteoporos Int. 2004;15(12):975-980.

25. Bianchi ML, Orsini MR, Saraifoger S, Ortolani S, Radaelli G, Betti S. Quality of life in post-menopausal osteoporosis. Health Qual Life Outcomes. 2005;3:78.

26. Wilson S, Sharp CA, Davie MW. Health-related quality of life in patients with osteoporosis in the absence of vertebral fracture: a systematic review. Osteoporos Int. 2012;23(12):2749-2768.

27. de Oliveira Ferreira N, Arthuso M, da Silva R, Pedro AO, Pinto Neto AM, Costa-Paiva L. Quality of life in women with postmenopausal osteoporosis: correlation between QUALEFFO 41 and SF-36. Maturitas. 2009;62(1):85-90.

28. de Oliveira Ferreira N, da Silva RB, Arthuso M, Pinto-Neto AM, Caserta N, Costa-Paiva L. Prevalence of vertebral fractures and quality of life in a sample of postmenopausal Brazilian women with osteoporosis. Arch Osteoporos. 2012;7:101-106.

29. Palacios S, Neyro JL, Fernández de Cabo S, Chaves J, Rejas J. Impact of osteoporosis and bone fracture on health-related quality of life in postmenopausal women. Climacteric. 2014;17(1):60-70. 
30. Oleksik AM, Ewing S, Shen W, van Schoor NM, Lips P. Impact of incident vertebral fractures on health related quality of life (HRQOL) in postmenopausal women with prevalent vertebral fractures. Osteoporos Int. 2005;16(8):861-870.

31. Oleksik A, Lips P, Dawson A, et al. Health-related quality of life in postmenopausal women with low BMD with or without prevalent vertebral fractures. J Bone Miner Res. 2000;15(7):1384-1392.

32. Silverman SL, Minshall ME, Shen W, Harper KD, Xie S. Health-Related Quality of Life Subgroup of the Multiple Outcomes of Raloxifene Evaluation Study. The relationship of health-related quality of life to prevalent and incident vertebral fractures in postmenopausal women with osteoporosis: results from the Multiple Outcomes of Raloxifene Evaluation Study. Arthritis Rheum. 2001;44(11):2611-2619.

33. Al-Sari UA, Tobias J, Clark E. Health-related quality of life in older people with osteoporotic vertebral fractures: a systematic review and meta-analysis. Osteoporos Int. 2016;27(10):2891-2900.

34. Hallberg I, Rosenqvist AM, Kartous L, Löfman O, Wahlström O, Toss G. Health-related quality of life after osteoporotic fractures. Osteoporos Int. 2004;15(10):834-841.
35. Cortet B, Blotman F, Debiais F, et al. Management of osteoporosis and associated quality of life in post menopausal women. BMC Musculoskelet Disord. 2011;12:7.

36. Roux C, Wyman A, Hooven FH, et al. Burden of non-hip, non-vertebral fractures on quality of life in postmenopausal women. Osteoporosis International. 2012;23(12):2863-2871.

37. Kerschan-Schindl K, Patsch J, Kudlacek S, Gleiss A, Pietschmann P. Measuring quality of life with the German Osteoporosis Quality of Life Questionnaire in women with osteoporosis Der deutschsprachige Osteoporosis Quality of Life Questionnaire zur Evaluierung der Lebensqualität bei Frauen mit Osteoporose. Wien Klin Wochenschr. 2012;124(15-16):532-537.

38. Borgström F, Lekander I, Ivergård M, et al. The International Costs and Utilities Related to Osteoporotic Fractures Study (ICUROS) quality of life during the first 4 months after fracture. Osteoporos Int. 2013;24(3):811-823.
Clinical Interventions in Aging

\section{Publish your work in this journal}

Clinical Interventions in Aging is an international, peer-reviewed journal focusing on evidence-based reports on the value or lack thereof of treatments intended to prevent or delay the onset of maladaptive correlates of aging in human beings. This journal is indexed on PubMed Central, MedLine,

\section{Dovepress}

CAS, Scopus and the Elsevier Bibliographic databases. The manuscript management system is completely online and includes a very quick and fair peer-review system, which is all easy to use. Visit http://www.dovepress. com/testimonials.php to read real quotes from published authors. 